\title{
RELACJA \\ O STANIE DIECEZJI KIJOWSKIEJ BISKUPA K.K. CIECISZOWSKIEGO Z ROKU 1793
}

OPRACOWAL I DO DRUKU PODAL

KS. BOLESLAW KUMOR 


\section{WSTEQP}

Wśród 18-tu archidiecezji i diećezji Polski niepodległej najmniej dotąd interesowano sie dziejami lacińskiej diecezji kijowskiej. Obok wartościowego artykułu pióra ks.' Karola Niedziałkowskiego, póńniejszego biskupa luckożytomierskiego ${ }^{1}$, oraz niewielkiego studium ks. T. Długosza, opartego głownie na relacjach procesów informacyjnych biskupow kijowskich ${ }^{2}$, oraz nowszego studium T. M. Trajdosa ${ }^{3}$, niewiele wiemy o tej kresowej diecezji. Najbardziej daje sie odczuc brak archiwaliów, bedących rezultatem działalności kijowskiej kancèarii biskupiej tak biskupów, jak i ich oficjałów generalnych. Wiadomo, że przed rewolucja bolszewicką w Rosji znajdowaly się one w Żytomierzu. Po aresztowaniach księży i administratora apostolskiego diecezji ks. Teofila Skalskiego, którego skazano na długoletni pobyt w lagrze (17 I 1928), budynki koscielne wraz $z$.katedra zostaly zabrane przez władze sowieckie. Nie wiadomo co się stało z archiwaliami diecezji kijowskiej i żytomierskiej. Szczególną przeto wartosć posiadaja dla dziejów tej diecezji archiwalia watykańskie w formie procesów informacyjnych biskupów kijowskich, a także relacje o stanie tej diecezji $^{5}$

Dzięki pasji badawczej arcybiskupa Franciszka Albina Symona, rektora Akademii Duchownej w Petersburgu (1884-1891), a póniniej biskupa pomocniczego mohylowskiego (1894-1897) i biskupa diecezjalnego płockiego (1897), a w koncu wygnańca ${ }^{6}$, zachowal się rekopis relacji o stanie diecezji kijowskiej z 1793 r. w Archiwum Kapituły Metropolitalnej w Krakowie. Wedlug relacji biskupa Walentego Wojcika w Archiwum Watykańskim znajduje się 7 relacji o stanie diecezji kijowskiej z lat:1607, 1617, 1739, 1754, 1756, 1784 i $1793^{7}$. Można przypuszczać, że relacje z 1754 i 1756 r. stanowia jedna, a nie dwie relacje. W drugiej zapewne chodzi o odpowiedź Kongregacji Soboru z 1756 r. na relację biskupa Kajetana Soltyka z 1754 r. Relacja z 1793 r. stanowi wartościowy

${ }^{1}$ K. Niedzialkowski, Kijowskie biskupstwo, w:Encyklopedia Kościelna Nowodworskiego, T. 10:1877, s. $330-345$.

2 T. Długosz, Z dziejów biskupstwa kijowskiego, Lwów 1932.

${ }^{3}$ T. M. Trajdos, Kosciól katolicki na ziemiach ruskich Korony i Litwy za panowania Wtadystawa Jagielty, (1386-1434), T. 1 Wroclaw 1983, s: 27-71.

'H. Stehle, Die Ostpolitik des Vatikans 1917-1975, München 1975, s. 144; M. Iwanow, Kościól katolicki w ZSRR wobec radzieckiej polityki wyznaniowej 1921-1928, w:Chrześcijaństwo w Zwiazku Radzieckim, Warszawa 1992, s. 106.

${ }^{5}$ B. Kumor, Katalog mikrofilmów Osrodka Archiwów, Bibliotek i Muzeów Kościelnych przy Katolickim Uniwersytecie Lubelskim, Nr 1 Lublin 1963, s. 41-42.

${ }^{6}$ E. H. Wyczawski, Symon Franciszek Albin, SPTK T. 3 (1983), s. 237-239.

${ }^{7}$ W. Wójcik, Wizytacje biskupów polskich „ad limina" do roku 1913, „Prawo Kanoniczne” 18:1975 $\mathrm{nr} 3-4$, s. 164. 
dokument historyczny, sporządzony w Żytomierzu w kancelarii biskupa K. K. Cieciszowskiego. Relacja ta ma charakter brudnopisu, na który naniesiono szereg dopisków i informacji prawdopodobnie ręką samego biskupa. Dzięki temu relacja ma specjalną wartosc. Wydaje się, że została ona przekazana Kongregacji Soboru przez pelnomocnika biskupa Cieciszowskiego. Urodził się on na Podlasiu (Wolyń 12 I 1745), ale od 1775 r. jako biskup koadiutor z prawem następstwa (prekonizowany $29 \mathrm{~V}$ 1777) przebywal w diecezji kijowskiej, od 1785 r. jako biskup tej diecezji. Byl to „maż wiary spiżowej $i$ apostolskiej gorliwości, dla siebie surowy asceta, czarem swej pokory, prostoty i ewangelicznej slodyczy, podbijał serca ludzkie" (abp Michał Godlewski) ${ }^{8}$. Takie rysy jego charakteru nosi rówinież publikowana relacja z $1793 \mathrm{r}$.

Jest to ostatnia relacja o stanie tej diecezji, która w tym samym roku na skutek drugiego rozbioru Polski przeszła pod panowanie Rosji, a ukazem carycy Katarzyny II z 27 IX 1795 r. została zniesiona. Kanonicznej kasaty diecezji dokonał legat apostolski Wawrzyniec Litta dekretem De apostolicae plenitudine z 8 VIII 1798 r. 9 .

Znamy wprawdzie diecezje $\mathrm{i}$ jej organizacje $\mathrm{z}$ opisu ks. K. Orłowskiego z 1748 r. $^{10}$, ale relacja z roku 1793 swiadczy o dużym rozwoju diecezji, zwłaszcza za rządów biskupa Cieciszowskiego. Informuje więc o miastach (3), miasteczkach (6) i wsiach (1760) diecezji. Mówi o zniszczeniu katedry w Żytomierzu przez trzęsienie ziemi, a następnie przez pożar oraz o jej odbudowie przez biskupa Cieciszowskiego. Pisze o kapitule i kolegiach kleru katedralnego, o sieci parafialnej, obejmujacej ' 43 parafie lacińskie, podczas gdy w 1748 r. bylo ich tylko 14. Zakony prowadzily 9 parafii, pozostale były w administracji kleru diecezjalnego. W diecezji było 13 klasztorów messkich ${ }^{11}$. W Żytomierzu działało seminarium duchowne prowadzone przez Księży Misjonarzy, fundacji samego biskupa Cieciszowskiego $\mathrm{z}$ dobr mensy biskupiej. W szpitalu żytomierskim dla 10 chorych, fundacji biskupa J. A. Załuskiego, pracowały siostry szarytki. Relacja informuje o bogatej działalności społecznej i politycznej biskupa Cieciszowskiego na Sejmie Wielkim, o uzyskaniu na tymże sejmie subwencji państwowej na utworzenie dalszych 24 parafii w województwie kijowskim i braclawskim ${ }^{12}$. Ciekawe są informacje o formach duszpasterstwa parafialnego, o ratio studiorum w żytomierskim seminarium duchownym itp. To bogactwo informacji zasługuje

${ }^{8}$ R. Ritzler, F. Sefrin, Hierarchia catholica medii et recentioris aevi, Vol. 6 (1720-1799) Patavii 1958, s. 248; M. Godlewski, Cieciszowski Kasper Kazimierz, PSB T. 4 (1938), s. $38-39$.

${ }^{9}$ B. Kúmor, Granice metropolii $i$ diecezji polskich 968-1939, ABMK 19:1969, s. 376.

${ }^{10}$ K. Orłowski, Defensa biskupstwa i dyecezyi kiiowskiej ..., Lwów 1745, s. 82-150.

${ }^{11}$ L. Bieńkowski, J. Kłoczowski, Z. Sułowski, Zakony meskie w Polsce w 1772 roku, Lublin 1972, s. 67; bylo wówczas w diecezji 30 parafii i 18 klasztorów.

12 Volumina legum, T. 9 [Kraków] 1889 nr 444, s. 438. 
w pelni na publikacje omawianej relacji wraz z notami marginalnymi, które uzupełniają i poszerzaja wiadomości na temat diecezji kijowskiej.

\section{Relacja o stanie diecezji kijowskiej z 1793 r.}

Archiwum Kapituly Metropolitalnej w Krakowie. Teki abpa Symona. Sygn. S. Sta 3 ss. $1-16$.

[s. 1]Relatio status Ecclesiae et Dioecesis Kijoviensis Sacrae Congregationi Concilii per me Gasparam Columna Cieciszowski ${ }^{13}$ episcopum Kijoviensem et Czernichoviensem circa visitationem sacrorum liminum 1793 -tio anno facta.

Eminentissimi ac Reverendissimi Domini Domini Patroni Singularissimi.

Cum in ovili Christi custodis gregis Summo Pastori et Domini in terris Vicario debitam obedientiam, perennem cultum, ex muneris sui rationem reddere sunt obstricti; mihi, qui huius Apostolicae Sedis gratia cathedrae Kijoviensi praesulatu fungor, nihil magis cordi est, quam ex omnis et singula, que patrum decretis et ss. canonum statutis circa episcopalis officii administrationem constituta et mandata sunt, salva integra ac inviolata servare. Quocirca relationem de statu Ecclesiae et Dioecesis meae Kijoviensis Sanctitati Suae ${ }^{14}$ et sacrae Congregationi ea, qua par est, reverentia, transmitto in modum, qui sequitur:

Primum relationis caput pertinens ad statum Ecclesiae materialem.

1. Ex speciali gratia Sanctissimi in Christo Patris Domini, Domini nostri Pii papae VI feliciter regnantis, praevia postulatione [s. 2] Serenissimi Stanislai Augusti Poloniarum regis ${ }^{15}$ in coadiutorem cum futura successione episcopatus Kijoviensis assumptus ${ }^{16}$, et in episcopum Sebastenensem 1775 anno consecratus $^{17}$, successi in cathedram Kijoviensem morte et obitu ${ }^{18}$ Francisci

${ }^{13}$ Kasper Kazimierz Cieciszowski, biskup koadiutor (1775-1785) i diecezjalny kijowski (1785-1795), następnie latyczowski (1795-1798), hucki (1798-1828) i metropolita mohylowski (1827-1831). M. Godlewski, Cieciszowski Kasper Kazimierz, PSB T. 4 (1938), s. 38-39.

14 Pap. Pius VI rządził Kościolem w latach 1775-1799.

${ }^{15}$ Stanisław August Poniatowski, król Polski (1764-1795). Abdykowal 25 VI 1795 r. Zmarł w Petersburgu w 1798 r.

${ }^{16}$ Ciecişzowski mianowany przez króla Stanisława Augusta Poniatowskiego koadiutorem z prawem następstwa kijowskim (13 III 1775), został prekonizowany na to stanowisko przez pap. Piusa VI w dniu 29 V 1775 r., Hierarchia catholica, t. 6, s. 244.

${ }^{17}$ Konsekracja biskupa Cieciszowskiego odbyla sie w Warszawie 10 sierpnia 1775 r., a głównym konsekratorem był biskup poznański Andrzej St. Młodziejowski. Zob. „Gazeta Warszawska" z 11 X 1775 r. 
Ossoliński ${ }^{19}$ vacantem 1784 anno, et regimen pastoralem concrediti mihi ovilis cum benedictione Sanctae Sedis in dioecesi Kijoviensi assumpsi.

2. Confinia ${ }^{20}$ dioecesis meae ad orientem Imperium Russiae, ad meridiem dioecesis Kamenecensis, ad occasum dioecesis Luceoriensis, ad septemtrionem dioecesis Vilnensis.

3 Praerogativa episcopatus consistunt in dignitate senatoria Regni. Cum episcopus sedem suam inter episcopos Chelmensem et Camenecensem obtinet et in comitiis generalibus una cum ministris Regni et palatinis libera pro utilitate

10 Skreślono wyrazy: „Illustrissimi et Excellentissimi ac Reverendissimi Domini”.

${ }^{19}$ Biskup Ignacy Franciszek Kandyd Ossoliński (1732-1783), franciszkanin konwentualny (1749), koadiutor bakowski (1768), a nastepnie koadiutor (1773) i diecezjalny kijowski (1774). Zmarl 7 VIII 1784 r. W. Müller, Ossoliński Ignacy Franciszek, PSB T. 24 (1979), s. 395-396.

${ }^{20}$ Tekst dopisany druga reka na marginesie s. 2-4:,constructa est sub invocatione s. Catharinae in locum ligeae ecclesiae cathedralis de latere cocto per antecessorem nostrum Christophorum Kázimirski circa annum 1600. De prima fundatione huius episcopatus, cum nulla in Archivio Ecclesiae meae extarent munimenta, tot vicisitudinibus rerum deperdita, curavi quam efficatius undequaque haec collegi, et quamvis de origine huius sedi nihil certi constat et ex dictis historicis erui potuisset, tamen conicitur hunc episcopatum a Boleslao Chrobry nuncupato circa annum Christi 1021, post devictos Russos, fundatum, ac in post multis devastationibus huius provinciae ab Roxolanis et Scythis ad nihilum redactum, per Vladislaum Jagiello regem Poloniae, devictis in proelio ad Grunwaldum Prutenos, anno 1412 ex voto restaurasse sedemque episcopatus Kijoviae fecisset. Bonae memoriae praedecessor noster Boguslaus Roża Radoszewski in anno Christi 1626 fundationes per certa loca mensae episcopali sex praelatorum totidem canonicorum, 12 vicariorum de consensu Urbani VIII papae oxornavit et titulis super totidem parochialium destinavit. In hac sede ultimus praedecessor noster Thomas de Rupniewo Ujejski circa annum Christi 1656 sedit. Capta enim a duce Moschoviae civitate Kijovia cum medietate maiori ducatus Kijoviensis parte.

Kijovienses praesules, amissa sede, bona mensae episcopalis et fundatione devastata manu hstilitate Russiae [...] ad annum 1720, sub tuitione divina peragentes et improperiis osculantes et per felicis recordationis Samuel Ożga praedecessorem nostrum constructa [...] ecclesia cathedralis [...] in' civitate Żytomierz (quae est nunc capitalis provinciae post amissam Kijoviam) de latere cocto sub invocatione Assumptionis B.M.V. et S. Sophiae, 6 titularis capituli, adornata sacra supellectili, dodatis pro suo posse 4 vicariis congruenter, capitularibus conditis statutis salubribus, ad novam cathedralem ecclesiam advenit. Pro successu temporis in anno 1743 Benedictus XIV PP. per suum breve concessit praelatis 7 et totidem canonicis usus crucis aureae octogenae cum mantoletto purpureo obsonio, ac radiis aureis intermedio, in cuius rato Aquilae, in alio [...] in medio s. Josephi, in verso vero $S$. Sophiae imagines reperiuntur, super aurea catenula, vel amenta violacei, vel alii coloris depicta, pendentes, tum usu mozetto [...] violacei coloris et rochetto adornati, indulgentiis condecoravit, et in parte Ignatius Soltyk, Josephus Załuski, Franciscus Ossoliński, praedecessores nostri, fundationibus seminario alumnorum, vicariorum et residentiis clero cathedrali [...], sed conflagrata anno 1760 ecclesia cathedrali [...] et reductis mediatim proventibus ecclesiae per statuta Regni, ecclesia ruina minatur, et pro sustentando clero [...] ecclesiae redditus non sufficerent. Deo adiuvante pro novae ecclesiae cathedralis extructione prima vice, Deo adiuvante et benedictione Sanctae Sedis, me adstringor". 
Ecclesiae et Reipublicae dat suffragia. Capitulum itidem suum quotannis liberis votis eligit e gremio sui iudicum deputatum, qui in Supremo Regni Tribunali una cum iudicibus saecularibus causas ultimae instantiae definit et diiudicat.

4. [s. 3] Civitates in episcopatus sunt tres:Żytomierz, ubi cathedra episcopalis translata de civitate Kijovia, Owró $\mathrm{cz}^{21}$ et Zwinogrodka ${ }^{22}$, in quibus iudicia districtus eiusdem nominis agitantur et scholae publicae extant sub directione religiosorum Ordinis s. Basilii Magni. Oppida sunt 6 numero, villae et pagi numero 1760 .

5. Statui materiali cathedralis ecclesiae olim terrae motu, dein conflagratione viliato, licetsi reparatione fuerant datae suppetiae, nihilominus eadem ecclesia, ut ei quontocius succuratur, non iam melioratione, sed de nova radice extructione opus habet, quod et pro dignitate eiusdem ecclesiae metricis et pro commodo christiani populi, licetsi iam pridem perficere in votis habui, nequaquam tamen voti compos extare valui, cum majestas ecclesiae ingentis sumptus exigere videbatur, quibus pendendis impar fueram. Ut vero nullum praetermitterem modum, quo cultus Dei augeri posset, exemplo et litteris pastoralibus christifideles ad contribuendum pro fabrica cathedrali allicui, enumeratis ipsemet mille aureis Hungaricalibus et facta execuratione pro sex operariis [s. 4] usque ad consummationem fabricae meo aere sustentandis, obtinui a dioecesanis meis collectas, quae errogantur in auctionem continuam materialium, structurae eiusmodi 'fabricae necessariorum. Spero faventibus Supernis et praevia Sanctae Sedis Apostolicae benedictione fundamenta ecclesiae cathedralis quam primum ponenda fore. Ad praesens divina officia in veteri ecclesia peragantur. Capitulum cathedralis (ecclesiae) constituunt octo dignitates et duodecem canonici. Collegium vicariorum, servitio chori addictorum, constat personis sex. Mansionarii pro decantando quotidiano cursu seu Officio parvo M.V. Mariae extant quatuor. Praebendae poenitentiaris et Theologalis erectae sunt. Prima tantum habet per me assignatos redditus pro sustentando poenitentiario.

o. Parochiales ecclesiae extant quadraginta tres, quarum novem sunt sub regimine regularium curam animarum exercentium, reliquae sub administratione curatorum ex clero. Monasteria cum [s. 5] ecclesiis religiosorum curam animarum habentium sunt quatuor, oratoris privata numero 8. Ecclesiae parochiales supellectibus satis sunt provisae. Licetsi separatos redditus pro fabrica assignatos non habeant, cura tamen patronorum, quibus iura praesentandi parochos ad

${ }^{21}$ Owrócz, przed 1793 r. miasto powiatowe w województwie kijowskim.

22 Zwinogródka, miasto na Ukrainie na poludniowy zachód od Kijowa. 
easdem ecclesias pertinent, tum solicitudine suorum rectorum in sartis tectis congrue sustentantur.

7. Collegiata ecclesia in dioecesi Kijoviensi non extat.

8. Monasteria religiosorum curam animarum exercentium sunt novem. In summa monasteria virorum tredecem. Nullum ipsorum immediate iurisdictioni episcopali subest. In iis tamen, quae sacri canones demandant, sive quae curam animarum respiciunt a iurisdictione ordinarii non eximuntur. Monasteria monialium non extant.

9. Seminarium clericorum circa ecclesiam cathedralem est sub cura et regimine Clericorum S. Vincentii a Paulo Missionariorum nuncupatorum. Clerici in eo aluntur sex. Nullum beneficium habet unitum. Redditus eius sunt 5500 flor. polon., qui cum consensu Sedis Apostolicae ex bonis mensae episcopalis quotannis [s. 6] venduntur pro sustentatione tam professorum seminarii, quam alumnorum, qui victum non solvunt, sed eiusmodi pensione sustentantur.

10. Hospitale circa cathedram a praedecessore meo Josepho Zaluski ${ }^{23}$ in fundo ecclesiae cathedralis de consensu capituli mei erectum et fundatum, sub cura Sororum Charitatis s. Vincentii a Paulo extat unum, quod varias summas, quibus bona terrestria sunt onerata, in unam massam collectas habent 120000 flor. polon., ex quibus annuus proventus expanditur in alimenta et educationem 120 puellarum et sustentationem 10 infirmorum $^{24}$. In dioeces $i^{25}$ penes quamlibet ecclesiam parochialem extat hospitale, in quo pauperes parochiani solis eleemosinis aluntur, et eiusmodi hospitalis redditus certos non habent. Collegium educationi iuventutis Żitomiriae extat unum, aliud Owruciae. Loca pia et confraternitates, redditus fixos habentes, non extant.

\section{Montes pietatis non reperiuntur.}

Secundum relationis caput pertinens ad ipsum episcopum.

1. Residentiae praeceptum, in quantum [s. 7] cum aegra valetudine mea et maiori Reipublicae ac Ecclesiae utilitate subsistere potuit, adimplere conatus sum.

${ }^{23}$ Józef Andrzej Zaluski (1702-1774), biskup kijowski (1758-1774), deportowany do Rosji (1767-1773). Razem z bratem Andrzejem Stanisławem fundator Biblioteki Narodowej (1747). J. Wysocki, Zaluski Józef Andrzej, SPTK T. 3 (1983), s. 517-525.

${ }^{24}$ Dopisano na marginesie s. 6: „a praedecessore Josepho Zahuski [...] ecclesiae cathedralis de consensu capituli mei erectum et fundatum".

${ }^{25}$ Dopisano tekst (s. 6): „Sed hic proventus, cum pro sustentandis et alendis infirmis generalem visitationem capituli mei de nonnullis proventibus ecclesiae huic in specie succurendo quotannis 450 flor. polon. subveniens, assignavi, et super eo cum consensu capituli mei ordinationem capitularem confici. In reliquo piis eleemosinis a fideli populo sustentantur". 
$\mathrm{Ab}$ anno 1788, in quo generalis Regni comitia praesentiam episcoporum tanto magis urgebant, quo uberiores fructus ex iis pro Ecclesiae et Patriae bono provenisse potuerant, Varsaviae commoravi, muneris mei fuerat. Saepius tamen dilectam mihi gregem litteris pastoralibus alloquebar, et consiliis ordinum generalium praesens fidem sanctam et bonum universalis Ecclesiae, bono Patriae meae anteponere studui continuo in condendis legibus, prae oculis habendo ea tantum Regni statuta, Patriae proficua et civibus utilia fore, quae fidei sanctae et legibus Ecclesiae sunt consona, eaque tanto maiorem incolis felicitatem adferre, quanto strictius ipsorum corda unum Dei cultus et fidei nexu ligantur.

2. Dioecesis mihi commissae visitationem tum in persona, tum per archidiaconos peregi. Decani foranei, mea ordinatione mediante, peragunt quotannis et de munere suo mihi ac Officio Generali rationem reddunt. [s. 8]

3. Sacras ordinationes in dioecesi praesens ipsemet peregi. [Decani foranei et] sacramentum confirmationis administravi. Dum autem ob negotia Reipublicae tractanda in comitiis generalibus, ut praemissum, a dioecesi abesse debui, expetivi a Sacra Sede Apostolica concessionen mihi, et consecrationem episcopi auxiliaris $^{26}$, qui functiones episcopales in locum mei supplevit, suppletque.

4. Synodum dioecesanam in tam ampla et dissista dioecesi cogere arduum et vix possibile est. Cum prolexitas temporis ipsi itineri conficiendo usque in locum synodi necessaria, privantur christifideles spirituali auxilio, atque non esset, qui parvulis panem frangeret et sacramenta administraret. In locum synodi viros eruditos et omni ex parte probatos in officium decanorum institui, qui ecclesias visitant, clero invigilant, observationem sacrorum canonum urgent et de moribus cleri Officium meum certum faciunt.

5. Verbum Dei in dioecesi praesens per me ipsum praedicavi. Concionatorem in ecclesia cathedrali, canonicum ex gremio capituli, constitui, qui huiusmodi [s. 9] praedicationis munus salubriter exequitur.

${ }^{26}$ Michal Pałucki, biskup pomocniczy kijowski, prepozyt wieluński, archidiakon czernichowski, urodzony w Dębnie w diecezji kijowskiej i ochrzczony 10 VIII 1745 r., wyświęcony na kapłana i promowany na doktora prawa kanonicznego w Akademii Zamojskiej 29 VI 1778 r., prekonizowany na biskupa pomocniczego kijowskiego 19 XII 1791 r. Hierarchia catholica, t. 6, s. 65 . 
6. Taxa Innocentiana ${ }^{27}$ in cancellaria tam curiae meae, quam officii generalis cum vix sit in usu in hoc Regno, non servatur ${ }^{28}$. Cum cancellarius annua stipendio ex proventu mensae episcopalis sibi pendi solito, est conductus pr labore. Et scriptura, super quod liberalitas dantium sponte ipsi subministrat voluerit.

7. Divina favente gratia sicuti raro in dioecesi Kijoviensi contiguntur culpa ita rarae sunt poenae, quae piis locis applicantur.

8. Adusque nihil quidquam circa episcopalis officii exercituum mihi obes nosco.

9. Non vanae gloriae cupiditate ductus, id quod boni pro Ecclesia pereger exarare intendo. Cum secundum scripturam scit Dominus, quod abominer signu superbiae et gloriae meae, sed Deo omnipotenti persolvendo gratias, ex quo omr bonum promanat, quod peragere indulsit, et Sacrae Congregationis obtemperand mandatis, quae peracta sibi innotescere desiderat. [s. 10] Sequentia, licet modica, sint Dei gloriae augmento, a primo in cathedram ingressu, sollicitudine meam converti ad ea, quae Dei cultum, animarum salutem et domus D ornamentum respiciunt, exemplo et doctrina populo mihi commisso praees volui. Seminarium circa cathedralem ecclesiam meam pro institutione iuventu sub regimine Presbyterorum Congregationis s. Vincentii a Paulo erigi et dota pro sex alumnis et tribus professoribus, ut actum superius, curavi. Supelectile ecclesiae cathedralis auxi, et ex bonis mensae meae episcopalis quotannis p1 linteaminibus flor. polon. ducentos solvendos assignavi. In anno 1788, quo fam his in oris divina permissione grassabatur, egentibus panem subministravi, de qu testimonium sit. Comitiis generalibus Regni Serenissimi Regis ore et ordinu Reipublicae acclamatione animam meam humiliavit timoreque affecit, ne id quc ex debito officii mei peregi, laudibus humanis elatum, divinam mihi mercede auferat, quam unice exoptavi. In iisdem comitiis fundationem et ex dotatione sumptu Reipublicae [s. 11] viginti quatuor ecclesiarum parochialium procuravi ${ }^{2}$ Tributa, quibus bona Ecclesiae oneranda fuerant, cura et solicitudine mea minu

${ }^{27}$ Taxa Innocentiana, wydana w 1676 r. przez pap. Innocentego XI. Zob. W. M. Plöch Geschichte des Kirchenrechts, Bd 4 Wien 1966, s. 75.

${ }^{28} \mathrm{Na}$ marginesie dopisano [s. 6]: „Praeter duo hospitalia ad ecclesiam Pilavecense Kotelavensem, et Ryszczoviensem sub cura religiosorum Ssmae Trinitatis de redemptio captivorum, ubi pro sustentandis aliquot personis, senio confectis, licet modicus, perpetu tamen fundus super inscriptione certarum summarum victualium".

${ }^{29}$ Sejm Wielki konstytucja z 8 IV 1792 r. na wniosek biskupa Cieciszowskiego postanou uposażyć 24 nowe parafie w województwie kijowskim i braclawskim. Zob. Volumina legun T. 9 Kraków 1889 nr 444, s. 438. 
ecclesias modicos proventus habentes a tributo subsidii charitativi persolvendo liberavi. Fundum mensae episcopalis in controverso cum bonis terrestribus existentem certis limitibus designavi feci ${ }^{30}$. Pro fundatione ecclesiae cathedralis mille aueros Hungaricales reponi et sex operarios meo sumptu sustentandos constitui. Meditationes seu exercitia spiritualia singulis diebus dominicis et festivis in ecclesia cathedrali peragenda demandavi. Pro danda unanimi modo christifidelibus doctrina christiana libros ad id aptissimos selegi, et mea opera in Polonicum idioma traductos, sumptu proprio imprimendos curavi. Rogo Deum datorem omnium, ut maiora meditanti et gratia et modus non desit, quo pie gratior et Ecclesiae utilior meae esse possim.

Caput tertium ad clerum saecularem pertinens.

1. Canonici distributiones ${ }^{31}$. quotidianas non habentes ad continuam residentiam non obligantur, vicarii et mansionarii [s. 12] choro quotidiano intersunt.

2. Matutinum, laudes caeterasque horas iidem vicarii in choro persolvunt, Missam conventualem pro benefactoribus applicatam celebrant, constitutiones suas punctualiter observant.

3. Praebenda poenitentiaria cum sit uni ex gremio capituli collata, idem continuo circa ecclesiam cathedralem residet, in sede confessionali poenitentibus praesto adest et suo muneri satisfacit.

4-8. Parochi in suis parochiis resident, libros metrices baptizatorum, copulatorum et mortuorum ad normam Ritualis Romani retinent. Sunt qui indigent aliorum sacerdotum opera pro commodiori administratione sacramentorum, sed ob penuriam cleri saecularis, opera et auxilio regularium uti coguntur, vel per seipsos sacramenta administrant.

${ }^{30} \mathrm{Na}$ marginesie [s. 11] dopisano: „Bonis mensae episcopalis, ecclesiam cathedralem, iniuria temporum collapsam, impensis meis exiguis propriis de novo construxi, et communicato cum capitulo meo consilio in dote aduxi, limitibusque circumsaepivi”.

${ }^{31}$ Tamże [s. 11] dopisano: „Cum capitulares ecclesiae cathedralis, capta per imperatorem Ruaaorum Kijoviensi civitate, omnibus proventibus spoliati, suis stipendiis viletantur omnibus distributionibus carent, ita ad sctrictam residentiam continuam circa ecclesiam cathedralem et obeundas caeremonias [...] adigere non valent, statutum tamen a praedecessoribus meis, ut semper unus de gremio capituli circa cathedram residet, qui gereret curam circa directionem cleri cathedralis, ipse, qui omnibus diebus solemnibus de praecepto in ecclesia cathedrali functiones obibet, observari ordinavi". 
9-10. Parochi plerumque per seipsos raro et vix umquam per alios idoneos diebus dominicis et festis plebem sibi [s. 13] commissam pascunt, docendo praecipue ea, quae roborandum in sancta Romanae Catholicae et Apostolicae Ecclesiae fide magis capacitati parochianorum consona sunt, tum quoque dando necessaria ad salutem necessitate medii et praecepti tumque. instruendo in rudimentis fidei, inculcando obedientiam erga Deum, parentes et superiores, avertendo a vitiis et alliciendo ad virtutes,satis bono profectu eas doctrinas peragi, et populum christianum fructuum ex is capere nos $\mathrm{co}^{32}$.

11. Missa conventualis cum applicatione pro parochianis peragitur in singulis ecclesiis, in quibus exercetur cura animarum.

12. Ante admissionem ad primam tonsuram examinatus alumnus ex rudimentis fidei, producit testimonium legitimi thori, proborum morum, legere latine ac scribere debet. Ante admissionem ad quatuor minores ordines subit examen ex profectu in lingua latina, definitionum ordinum, maturam, formam, finem et effectum noscere tenetur et in seminario subire exercitia spiritualia [s. 14] et proficere in doctrina ad minimum duorum annorum, sacris ordinibus initiandi, vacandi piis meditationibus per dies quinque.

13. Non solum clerici in seminario degentes, sed etiam parochi et eorum vicarii ubique clericales et thalares etiam extra ecclesiam vestes deferunt. Quae ad privilegium fori servantur ea omnia, quae a sacris Trid. Synodo Sess. 23 cap. 6 de reformatione et a constitutione Sanctissimi Domini Nostri Papae Benedicto XIII sunt disposita, ac legibus Reipublicae non dissona ${ }^{33}$.

14. Conferentiae Theologiae moralis, casuum conscientiae et sacrorum rituum habent quotidie in seminario cum maiori semper profectu.

15. Mores cleri saecularis in dioecesi tam ampla et dissista inter schismaticos, sunt probi, et divina favente gratia nulli scandalo subiecti, immo bono exemplo praelucentes. Processus super obiectionibus vitae morum vix sunt auditi, nullumque adest scandalum, quod potentiori remedio indigeat [s. 15].

${ }^{32} \mathrm{Na}$ marginesie [s. 13] dopisano: , festis vero Domini et omnibus diebus tempore confessionis paschalis cathechismus explanatur ad captum rudioris populi [...] ex vicariis loci pro satisfaciendo Communionis Paschalis".

${ }^{33}$ Concilii Tridentini - canones et decreta. Cura G. Smets, Bielefeld 1858, s. 129. Sess. XXIII cap. 6; W. M., Plöchl, dz. cyt., Bd 3 Wien 1959, s. 261. 
Caput quartum ad clerum regularem pertinens.

1. Regulares curam animarum exercentes subsunt iurisdictioni, visitationi et correctioni episcopali, in iis omnibus, quae ad curam animarum et administrationem sacramentorum pertinent, munus suum parochiale fideliter adimplent.

2. Sunt qui de licentia suorum superiorum regularium in domibus nobilium morantur et functiones capellani aulici exercent. Eiecti ex monasterio ob delicta non reperiuntur, neque etiam ita extra claustrum delinquentes, ut delictum eorum essent notorium.

3. Authoritate delegata visitatio conventuum, in quibus non aluntur religiosi in numero a sacris constitutionibus praefixo est peracta, mores religiosorum in is conventibus extantium examine et scrutiniis adinventi sunt boni, nullumque scandalum praeseferentes.

4. Nullum iurisdictioni episcopali a religiosis causatur offendiculum in is omnibus casibus, quae delegata vel ordinaria auctoritate mihi cum ipsis procedere contigit, a iurisdictione mea non se eximunt.

Quintum caput ad moniales pertinens [s. 16].

Cum moniales in dioecesi Kijoviensi non extant relatio praesentis capitis omittitur.

Caput sextum pertinens ad seminarium.

1-4. In seminario ad cathedram Kijoviensem extant alumni sex, qui per presbyteros Congregationis s. Vincentii a Paulo in disciplina ecclesiastica recte instituuntur. Studia, quibus vacant, sunt theologia moralis et dogmatica, historia ecclesiastica, ius canonicum et Scriptura sacra ${ }^{34}$, in quibus proficiunt, et strictam ex profectu in ipsis reddunt rationem ante susceptionem sacrorum ordinum. Cathedrali ecclesiae diebus dominicis et festivis inserviunt.

5. Canonici duo, unus a capitulo, alter a me electus, provisores seminarii nuncupati, iuxta statutum S. Concil. Trident. seminario invigilant et mecum necessaria statuta condunt. [s. 17]

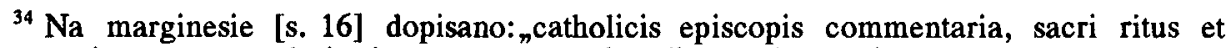
caeremoniae, cantus ecclesiasticus, ut vocant, choralis, ac eloquentia sacra”. 
6. Visitatio seminarii per me, per canonicos provisores iteratur, qui invigilant, ut constitutiones serventur.

7. Taxa nulla statuta est, cum expensae seminarii supplentur pensione pro eodem seminario cum consensu Sanctae Sedis facta ex bonis episcopalis, ex quibus dum quotannis penditur summa 5500 flor. polon. sufficiens est pro sustentandis sex alumnis et tribus professoribus seminarii.

Caput septimum ad ecclesias, confraternitates et loca pia pertinens.

Praeter ecclesias parochiales aliae ecclesiae in dioecesi Kijoviensi non reperiuntur. Confraternitates et loca pia redditus habentia non extant, quae autem reperiuntur circa visitationem generalem sunt reformati ${ }^{35}$.

Caput octavum pertinens ad populum.

Mores populi dioecesis meae Kijoviensis, divina auxiliante gratia et cleri exemplo ac sollicitudine mea [s. 18] magis laude, quam vituperio digni, licetsi in tritico reperiantur zizania. Et in Collegio Apostolorum proditor, ac vitiis donentur homines, non mihi tamen fas est conqueri super corruptione morum Dioecesis meae. Immo sanctae fidei fervor, frequens sacramentorum participatio, ingens ad ecclesias concursus, rarissima scandala, praebens indubitata indicia bonorum morum, cum quotidiano in virtutibus profectu, liceat mihi gloriari, cum gloria non est mea, sed Christi.

${ }^{35} \mathrm{Na}$ marginesie [s. 17] dopisano: ${ }_{n}$ Confraternitates, praesertim in ecclesias regularium circa visitationem generalem dioecesis, examinata et reformata, si qui irrepserint abusibus, piis et utilibus statutis sunt ordinata". 